temporary mental aberration the result of bodily disease? There can be no question whatever that an asylum of some sort is the best place for the patient, but he need not be certified as insane, at any rate, until it is seen whether his insanity is likely to be permanent or not. These are the cases which swell up the recovery rate of admissions to asylums, especially those suffering from alcoholic insanity, and $\mathrm{I}$ have always very much doubted the recovery rates from organic insanity. I would like to see established in Liverpool, preferably by the corporation, a reception house for mental diseases of all forms where patients might be admitted in the acute stage of the disease and kept under observation for one month, and at the end of that time, if the symptoms had not passed off, either be removed by their friends or then certified for detention in an asylum.

After a long observation of lunatics-and I have personally certified over 2000 patients to asylums-I am firmly convinced that a large number of people are certified as lunatics throughout the country who are simply suffering from temporary insanity the result of, or associated with, some form of bodily disorder or toxic poisoning. These people are not really insane and should not be associated with lunatics. They quickly recover under proper treatment and I maintain that from every point of view it would be to the public advantage for them to be treated in a hospital for mental diseases, with expert physicians in attendance and a clinique of students to study the acute phases of mental disorder, and where the patient and his relatives might be spared the stigma of his having been detained in a public lunatic asylum as a certified lunatic.

Liverpool.

\section{THE TREATMENT OF EARLY MENTAL CASES IN A GENERAL HOSPITAL.'}

\section{BX J. W. SPRINGTHORPE, M.A., M.D. MELb.,} M.R.C.P. LOND.,

PHySTCIAN TO THE MELBOURNE HOSPITAL; LECTURER ON THERAPEUTICS TO THE UNIVERSITY OF MELBOURNE: OFFICIAL VISITOR TO THE METROPOLITAN ASYLUMS, VICTORIA.

THE classical mistreatment of the lunatic was synchronous with the dominance of the metaphysical conception of the depravity of his volition, and died with its death, perpetuating its cruel existence, however, in the legal definition and procedure that still dare to misjudge man's responsibility by what the lawyers are pleased to call his knowledge. But the modern treatment of the insane, inspired as it is by the modern scientific spirit, is something very different and is ever advancing along lines of progressive reform, so that the phase of development of a community may almost be said to be mirrored by the manner and degree in which it deals with its mentally afflicted.

On looking round we find the following therapeutic details characteristic of the procedure of the most humane and scientific peoples-viz., some provision for early and doubtful cases in the shape of observation wards or receiving houses; the scientific classification of the insane; the separation of the curable in small wards or detached hospitals, furnished with all modern requirements and provided with fullytrained nurses in the proportion of at least one to five; the opening of outdoor departments ; the fusion of hospitals and asylums, and the establishment at the latter of a consultant medical, surgical, and neuro-pathological staff ; the transference of patients from one asylum to another; the licensing of wards in workhouses and the like for the harmless chronics; the boarding-out of increasing numbers by twos and threes in private families, and the official supervision of all private and individual cases. How far we in Victoria fall short of these signs of progress is known only too well to all who take an interest in lunacy matters, and the practical result with us has been that members of the profession here are often at a loss to know how best to deal with numerous individual cases. Too often, also, pauper lunatics enter the asylum through the doorway of the gaol, whilst some of our criminal insane have never got further than the inside of the gaol hospital. It is little wonder therefore that, wherever practicable, the better class are

I A paper read at the April meeting of the Medical Society of Victoria. either treated $s u b$ rosâ in private establishments or sent out of the colony to better quarters abroad.

It was in view of these unfortunate circumstances and their tacit recognition by the authorities that for some years past I have from time to time attempted to treat some of my insane patients in the wards of Melbourne Hospital. The Government provision was so unsatisfactory and inadequate, there was no receiving house, the very names of Kew and Yarra Bend carried an indelible stigma, whilst by hospital treatment there might be for the students in. valuable clinical material that they might otherwise never obtain, and for the patient earlier, and in many respects better, treatment. Most of the advantages of such hospital treatment require simply to be stated to be recognised and admitted:-1. There is no necessity to wait until someunfortunate accident, lâche, or crime necessitates the tardily-written certificate. Treatment is thus available much earlier than usual-a point the importance of which to the patient, to his friends, and to the community can scarcely be over-estimated. 2. It places "borderland " and early cases under the same therapeutic conditions that have been found efficacious against the kindred hysteria, cerebrasthenia, and bodily disease generally, and it gives the patient greater opportunity of having the frequent co-existing or causative bodily disease properly and promptly attended to. 3. It does away with the false distinction between mental and bodily disease and it altogether avoids the stigma and disgrace attaching to "lunatic" and "asylum." 4. There is no signing of certificates with its, at times, serious sequelæ to both patients and medical men, and the natural convalescing ground, the home, is much earlier and more readily available.

These are advantages, both fundamental and immense. But the plan has also its limitations and disadvantages. We had, and have, no cells for separate cases; the nursing staff was, and is, not organised for lunacy work or specially trained in lunacy charge ; whilst the hospital grounds are too small even for ordinary recreation and the public strain upon our beds, their much greater individual cost, and the restric. tions of the law are such as to render it impossible to deal with more than an occasional patient or to keep him under treatment for more than a limited number of weeks. Most, if not all, of these disadvantages, however, seem to me matters of arrangement rather than of principle.

My actual experience may be summarised as follows: 1. Under existing conditions it was found impossible to attempt to deal with maniacal cases. Outside the general wards there was no place for them except the refractory ward and that was fully occupied by the "D.T.'s," the cases of noisy delirium with fever, and the like, and structurally the building itself was quite unsuitable. 2 . We were, however, able to observe and to treat cases of early progressive dementia and of early general paralysis (especially those in which the mental symptoms were late in their development) until we were satisfied that the asylum was the proper place for them. 3. The hospital wards have also been excellent observation wards for many doubtful cases in which it was impossible to say definitely whether the mental condition was or was not the outcome of some undercurrent bodily disease but which, under any hypothesis, required skilled treatment forthwith. Under this heading I have thus dealt with cases of disseminated sclerosis; with mental crises; with cases of syphilitic frontal lepto-meningitis and brain tumours; and with the mental phases of uteroovarian disease, of hypochondriasis, and of doubtful general paralysis. It is beyond question that the critical atmosphere of a hospital medical school and the skilled reports and care of highly-trained sisters are of the greatest value in promoting the diagnosis and treatment of these mental conditions. Other cases, also, complicated with epilepsy, in which the epileptic status was frequent, or unusually severe, or in which the amnesia and dementia were becoming marked, or the onset of actual insanity was suspected, could be kept under observation until it was decided what was best to be done and meantime they could be treated to the best of our ability. 4. Cases of actual lunacy, also, in which the condition was undoubted but the necessity or advisability of signing certificates was more or less problematical, have been satisfactorily treated in the wards. Thus I have treated cases of transient mental unsoundness due to inanition, to. neglect, or concomitant with phosphuria, until the patients have been discharged cured. I have also treated cases of sudden dementia, stupor attonitus, and other diseases, due to shock, fright, and the like, until they, too, have regained 
their mental equilibrium. And, most interesting of all, I have taken into the wards a number of cases of actual melancholia and in three at least I had the satisfaction of seeing them rapidly restored to health without any recourse to asylum certificates or treatment.

One of these cases was that of a female, aged 24 years, of good family, but reduced circumstances, who, from the cheerless nature of her outlook, and some religious selfcondemnation, had become morbid, left her home before daybreak, and was found by a policeman half-dressed and wandering near the Yarra. She was speechless, declined her food, and had to be watched and looked after. Her medical attendant suggested asylum treatment, but after careful examination $\mathrm{I}$ undertook to try the effect of general hospital treatment. She was admitted into Ward 12 on April 24th, 1901, nursed, dieted, and otherwise treated according to the indications. She soon began to take notice, became interested, slept, ate, and conducted herself along normal lines, until in three weeks she was sufficiently recovered to be restored to her family, both they and she being very grateful for the restoration, and especially for the fortunate avoidance of asylum reminiscences.

The second case was that of a girl, aged 18 years, who had become cataleptic after typhoid fever and who made a good recovery in Ward 12;12 months later (May 11th, 1899) I was called to see her in a state of melancholic stupor after an acute onset. Here, again, there was no question of the need of prompt skilled atttention and justification even for asylum restraint but I decided to try the hospital before signing a certificate. A good deal of difficulty was experienced in dealing with her in a general ward but by the tact of the sister and the hearty coöperation of the nurses the patient was able to go home some seven weeks afterwards and came to see us a month later thoroughly well both mentally and bodily.

The third case was also one of a young girl, aged 18 years, always somewhat dull, and never rising above the third class at school. Partly from overwork in a factory and partly from excessive religious emotion she had become completely changed, melancholic, delusional, and was recommended by her medical attendant for asylum treatment. I took her, however, into the hospital on June 2nd, 1900. For a few days we had to send her down into the refractory ward, but six weeks later she was able to go away with her mother and was seen several months later as well as ever she was. In all three cases the hospital environment, the nursing, and the going out with different nurses, contributed very largely, in my opinion, to the early and satisfactory result.

This brief summary will suffice to show that the wards of a general hospital can fulfil a very useful function in the treatment of early mental diseases. And it is equally evident that, with some reorganisation and rearrangement, this new and specially valuable utility might be considerably augmented.

No doubt most of the present disastrous hiatus between the onset of mental unsoundness and its asylum treatment would be satisfactorily filled by the establishment of a receiving house, provided that receiving house was large enough to accommodate all suitable cases, was properly equipped, was provided with sufficient ground, and was officered and nursed along the lines of a general hospital. And its usefulness, in my opinion, would be quadrupled if an outdoor department could be added to it and its name and scope widened into that of a hospital for early mental cases. But until such a receiving house is actually receiving patients, and even afterwards, it would also, in my opinion, be a natural and proper part of the usefulness of a general hospital, which is also a medical school, to make suitable provision for the reception and treatment of a certain number of such cases, and it will be an endeavour on my part to bring the matter prominently under the notice of our hospital staff and committee.

Since writing the above $I$ have found strong corroboration of the position therein taken up in the report of a special meeting of the Edinburgh Medico-Chirurgical Society called to discuss the Treatment and Teaching of Incipient and -Transient Mental Disorders in the Royal Infirmary of Edinburgh. ${ }^{2}$ The meeting was a large and representative one and most of the managers of the Royal Infirmary of Edinburgh were present. Sir John sibbald introduced the question in a paper which claimed that the early stages of mental disease required just that kind of treatment that a general hospital could best offer, and that the establishment of wards in the Edinburgh Infirmary would best remedy advantages to be obtained from such a new departure and suggested a time-limit of six weeks, at the end of which asylum treatment might follow in case recovery or death had not taken place. He dwelt also upon the advantage to the medical student in thus becoming duly equipped for one of his most serious future responsibilities. He was supported by powerful speeches by Sir John Batty 'Tuke, Dr. 'T. S. Clouston, Dr. J. O. Affeck, Dr. Urquhart, and others, the chairman of the General Board of Lunacy, and the adviser in lunacy to the Glasgow Parish Council, all of whom recognised the extreme importance of the proposal and its educational, preventive, and curative value. Finally, it was unanimously agreed "that this meeting urges strongly on the managers of the Royal Infirmary the propriety of seriously considering the expediency of providing wards within or in the immediate vicinity of the institution for the treatment of incipient, transient, and recent cases of insanity."

Melbourne.

\section{TEMPORARY REMINISCENCE OF A LONG- FORGOTTEN LANGUAGE DURING THE DELIRIUM OF BRONCHO- PNEUMONIA. ${ }^{1}$}

BY HENRY FREEBORN, M.B. EDIN.

With Remarks by C. A. MERCIER, M.B., M. R.C.P. Lond., F.R.C.S. ENG.

THE patient was a woman, aged 70 years. She felt poorly on the evening of March 6th, 1902, and kept her bed on the 7th. I saw her on the 8th and found her complaining of headache and pain in the shoulders, back, and limbs. Her temperature was $102^{\circ} \mathrm{F}$. and her pulse was 100 , regular, and strong. Examination of the lungs revealed slight bronchial catarrh (the patient was very liable to slight attacks of bronchitis and had to keep her bed for a few days at a time once or twice during every winter). Her condition on the 9 th and 10th was about the same; there were less headache and pain generally, the temperature remaining between $101^{\circ}$ and $102^{\circ}$. On the 11th the patient had passed a bad night, the respirations were quickened, the cough was troublesome, the pulse was 120 , and the temperature was $105^{\circ}$. Examination of the lungs revealed increased bronchitis all over and on the right side of the back at the angle of the scapula increased vocal resonance and fine crepitations. There was no difference in the percussion note on the two sides. The lungs were not again examined thoroughly after this date until about the 20th because the condition of the patient would not allow it. When they were then examined the bronchial catarrh had disappeared all over. On the right side no trace of any patch of consolidation could be found, but on the left side at the back I found dulness over rather a large area with other signs of consolidation. This had quite cleared up three days after. The general condition of the patient remained about the same for two days, the temperature being between $105^{\circ}$ and $106^{\circ}$, the pulse at this time being about 120 and strong On the 13th the temperature fell rapidly to $98^{\circ}$, went up again for a short time in the afternoon to $101^{\circ}$, and fell again in the evening to $97^{\circ}$. On this day she coughed up a little rusty sputum, the only time she did so. At 9 P.M. I arrived to find her apparently dying. The pulse was quite uncountable, weak, and flickering. The nurse said that she began to change an hour before and was getting rapidly worse. Three minims of liquor strychniæ were given subcutaneously. In 10 minutes the pulse could be counted and in 20 it was fairly strong at 110 . It was found necessary to repeat this dose every fourth hour and to give brandy and carbonate of ammonia freely until the 16th, on which day she began to improve and her pulse remained strong and slow without the help of the strychnine. On the $16 \mathrm{th}$ and 17 th the bowels acted very freely six times in 24 hours; this was one reason for discontinuing the strychnine. Two doses of ${ }_{I \frac{1}{0} 0}$ th grain of digitalin were given on the 14th in conjunction with the strychnine, but the mixed injection did not act as well as the strychnine alone. The heart did not respond 